\title{
A review of the Tascam $\mathrm{CC}-222$ \\ Karl Fisher \\ University of the South
}

An ongoing challenge for language center coordinators and professors is to find a painless way to convert analog media to digital files. One solution is to connect a cassette deck directly to a computer and use an audio capture software program (such as SoundEdit 16) to convert the sound files to WAV or MP3 format: This is a tedious task, and the quality of the converted file is not always acceptable due to input levels, loss in the cables, or poor connections to the sound card. I recently needed to convert a set of tapes not available on $C D$ to the WAV (standard CD) format. After consulting with our media services director, I borrowed his Tascam CC-222 MKII cassette/ $\mathrm{CD}$ burner unit. Compared to my former method of hooking up a cassette deck to a computer, the conclusion was obvious: I needed one of these units for my lab!

The unit looks like a standard audio component and can be connected to a stereo system and used as a standard CD and cassette player. You can also copy $C D$ recordings to cassette. However, its most important feature is the ability to transfer cassette audio recordings to $C D$. The process is very straightforward:You insertablankCD-Rinto the unit, find thestarting point on the cassette, push record on the $C D$ unit, and then push play on the cassette controls. At the end of the recording, you push stop on the $C D$ unit, stop the cassette tape, and then the machine automatically creates another track on the $C D$. When you are donecreating tracks, you press the "FINALIZE" button on the remote or directly on the deck, confirm with the "ENTER" button, and you have a finished CD in under a minute.

The Tascam CC-222 MKII also works with a turntable by connecting the output cables and the ground wire to the back of the unit:Then $\mathrm{LP}$ records can be converted to $\mathrm{CD}$. Likewise, any other audio source (a microcassette player, for example) can be connected to the rear of the unit and $\mathrm{CD}$ can be created from that input. After CD conversion, the WAV files (standard CD tracks) can be easily converted to MP3s or QuickTime MOV files and uploaded to campus servers. (Be sure to consult and follow your institution's copyright policies and obtain appropriate permissions before converting and uploading audio files.) 
The only drawback of the unit is (because of its many features) the relative complexity of the controls. Setting the input source is like setting the clock on some VCR's: You have to carefully study the users' manual and follow the step-by-step instructions. Once the settings are established, the unit is very userfriendly. The suggested retail price is $\$ 950$. If you need to convert more than a few cassette tapes to digital format, it is worth every penny.Seehttp://www.tascamcontractor.com/products/CC222.html for more product details, photos, and even a downloadable PDF of the users' manual. •

Karl holds an M.A.T. in Spanish from the University of North Carolina at Chapel Hill. He is an Instructor of Spanish and Director of the Language Laboratory at the University of the South in Sewanee, Tennessee. 